\title{
Study on the Properties of UHMW-PE Film
}

\author{
Zhongyan Du, Jihu Wang, Shaoguo Wen*, Pengzhu Wang, Dongdong Zhang, Changle Yin \\ College of Chemistry and Chemical Engineering, Shanghai University of Engineering Science, Shanghai, China \\ Email: sg wen@qq.com, zhongyan du@163.com
}

Received 18 July 2015; accepted 18 August 2015; published 21 August 2015

Copyright (C) 2015 by authors and Scientific Research Publishing Inc.

This work is licensed under the Creative Commons Attribution International License (CC BY).

http://creativecommons.org/licenses/by/4.0/

(c) (i) Open Access

\section{Abstract}

Some physicochemical properties of UHMW-PE film such as gas permeability, tensile strength, and corrosion resistance in acid with different immersion time, various concentrations and various solutions and rattler testing were studied. The obtained results showed that the values of gas permeability, tensile strength, elongation at break, and the temperature of dissociation at weight loss $5 \%$ was $546.57 \mathrm{~cm}^{3} \cdot \mathrm{m}^{-2} \cdot 24 \mathrm{~h} \cdot 0.1 \mathrm{MPa}, 37.22 \mathrm{MPa}, 368.00 \%, 360^{\circ} \mathrm{C}$, respectively. In different concentration acid, the surface resistance of film accumulated to some extent with immersion time increasing, together with that the higher acid concentration was, the lower the surface resistance of film was. Moreover, the contact angle of films gradually increased with the acid concentration decreasing and the increase of immersion time. After wear testing, the mass of UHMW-PE film did not nearly change, while the contact angle became larger with the number of turning increasing and the value was more than $90^{\circ}$.

\section{Keywords}

UHMW-PE Film, Surface Modification, Surface Resistance, Contact Angle

\section{Introduction}

Ultra-high molecular weight polyethylene (UHMW-PE) has been widely applied to biomedical materials due to its superior chemical stability and its tribological and mechanical properties [1] [2]. The UHMW-PE is also used in the industry such as pickers for textile machinery, lining for coal chutes and dump trucks. However, some difficulties need to be overcome especially in tribological aspects that can extend the lifetime of UHMW-PE by reducing their wearrate. Other significant applications will include areas such chemical engineering, electronics, mining industry and transportation. This material applies especially for machine parts subjected to wear such as bearings, gears or chain guides [3] [4]. UHMW-PE is widely used as the material for artificial joints in the human body which has superior mechanical properties and stability [5] [6]. In other words, on account of the low

${ }^{*}$ Corresponding author. 
surface hardness and poor wear resistance of polymer, wear particles lead to osteolysis, this will cause joint loosening, bone loss, discomfort, and thus reduce the lifetime of the joints [7] [8]. As a consequence, much effort has been carried out to improve the mechanical and tribological properties of the UHMW-PE materials. Up to now, it has been suggested that crosslinked UHMW-PE (generated either by gamma irradiation or by peroxide treatment or thermal treatment) can dramatically enhance the wear resistance compared with non-crosslinked UHMW-PE [9] [10]. It not only can be deal with melt-drawn or calendar rolling methods in laboratory but also can be prepared of highly oriented, nanostructure. UHMW-PE film is usually manufactured by cutting the thickness of UHMW-PE board below $1 \mathrm{~mm}$ in industry. Hot compression molding is a new method which is expected to use for the industrial production of high-strength UHMW-PE film. We had investigated the performance of UHMW-PE film prepared by small section production line using double-roller hot compression molding, then hot pressing mold method by the third roller was characterized, finally, modified the surface of the film [11]. Our aim is to gain the change of surface resistance of UHMW-PE film modified by acid with different immersion time and various concentrations and little change of mass by wear testing.

\section{Experimental Procedure}

\subsection{Reagent}

38 wt\% $\mathrm{HCl}, 85$ wt\% $\mathrm{H}_{3} \mathrm{PO}_{4}$ and 99.95 wt\% $\mathrm{CH}_{3} \mathrm{COOH}$, Sinopharm Chemical Reagent Co., Ltd., AR; UHMWPE powder, Jiujiang Xinxing Fiberglass Material Co., Ltd. Thermopressing of mechanically activated powder was carried out using a hydraulic press MEGA KSC-10A under a load of $76 \mathrm{MPa}$. Then powder was heated to $160^{\circ} \mathrm{C}$ for $1.5 \mathrm{~h}$ and held at this temperature for $10 \mathrm{~min}$. Then, hot pressing with a load of $80 \mathrm{MPa}$ and cooling under pressure was performed [10].

\subsection{Acidation Modification}

The UHMW-PE films were immersed in different concentration ( $\mathrm{HCl}$ : $38 \mathrm{wt} \%, 30 \mathrm{wt} \%$, $20 \mathrm{wt} \%, 10 \mathrm{wt} \% ; \mathrm{H}_{3} \mathrm{PO}_{4}$ : $85 \mathrm{wt} \%, 30 \mathrm{wt} \%, 20 \mathrm{wt} \%, 10 \mathrm{wt} \%$; $\mathrm{CH}_{3} \mathrm{COOH}: 99.95 \mathrm{wt} \%$, $\left.30 \mathrm{wt} \%, 20 \mathrm{wt} \%, 10 \mathrm{wt} \%\right)$ of acid for $3 \mathrm{~h}, 6 \mathrm{~h}, 9 \mathrm{~h}$, and $12 \mathrm{~h}$ at $25^{\circ} \mathrm{C}$. Subsequently, the films were rinsed at more than three times using distilled water and dried in oven at $60^{\circ} \mathrm{C}$ for half an hour. The changes of surface resistance and contact angle of films were investigated.

\subsection{Wear Testing}

Setting the cylinder number 1000r, 1500r, 2000r, 2500r, 3000r, the UHMW-PE films were rubbed at $25^{\circ} \mathrm{C}$. The changes of mass and contact angle of UHMW-PE films were investigated.

\subsection{Characterization}

Thickness was tested by a Thickness tester (Lab think Instruments CO., Ltd., CHY-CA). Thermal degradation and the corresponding mass loss of UHMWPE were determined by Thermogravimetic analysis (TGA) (LINSEIS Instruments International, STA PT-1000) under Nitrogen protection at the rate of temperature 10 ${ }^{\circ} \mathrm{C} / \mathrm{min}$. The tensile strength and elongation at break was carried out by a Tensile testing machine (GOTECH Testing Machines CO., Ltd., GT-TCS-2000) according to GB/T 1040-2006. Surface resistance was tested by a High insulation resistance measurement instrument (Shanghai Anbiao Electronic CO., Ltd.) according to GB/T 1410-1989. The contact angle was measured by a Contact angle measuring instrument (Zhongchen Digital Technology Apparatus CO., Ltd., Shanghai, JC2000D2A).Surface morphology was visualized with a Scanning electron microscope using an acceleration voltage of $10 \mathrm{kV}$ (Hitachi High Technologies, S-3400N). Gas permeability was measured by a gas permeability Tester (Lab think Instruments CO., Ltd., BTY-B1P) according to GB/T 1038-2000. The wearing resistance was tested by a Paint Film Wear Tester under 500 grams load weight (Shanghai General Chemical Machinery Co., Ltd., JM-IV). Density was measured by a Precisa Density Meter (GOTECH Testing Machines CO., Ltd., GT-XS 365M).

\section{Results and Discussion}

\subsection{Physico-Chemical Properties}

The UHMW-PE film was conducted using a roll-processing machine in the selected temperature and pressure. 
Details of the materials examined. Properties of UHMW-PE film are displayed in Table 1.

According to the Table 1, the thickness of UHMW-PE film is unfixed. There is a $\pm 10.00 \mu \mathrm{m}$ difference of the UHMW-PE film thickness. It is difficult to control a certain and determined thickness. It indicates the thickness distributing of UHMW-PE film which processing by calendar rolling with conventional design roller is unfixed. However, it is all the same meet with industrial preparation method for the thick and wide range UHMW-PE film they need. Convex in the middle of hot compression roll must be optimum reduce the distance between the two rolls, we can obtain equithickness film. According to the studies of Petrican [3] and Huang [6], UHMW-PE films have excellent properties that tensile strength and elongation at break is $37.22 \mathrm{MPa}, 368.00 \%$, respectively. The gas permeability of UHMW-PE film is $546.57 \mathrm{~cm}^{3} \cdot \mathrm{m}^{-2} \cdot 24 \mathrm{~h} \cdot 0.1 \mathrm{MPa}$. UHMW-PE film is hopeful to be applied in occasions packaging and transporting materials on gravity transport occasions.

\subsection{Heat Resistance}

UHMW-PE film has superior properties in tribological aspects. The materials will increase temperature with rubbing long time. Heat build-up leads to the strength degradation owing to polymer materials chain breaking or thermal degradation. Therefore, this is so important that confirm the heat decomposition temperature for industrial application. TG and DTG curves of UHMW-PE film are shown in Figure 1.

According to Figure 1, the sample weight loss $5 \%$ and $95 \%$ occurs at $360^{\circ} \mathrm{C}, 530^{\circ} \mathrm{C}$, respectively. When the temperature rose to $540^{\circ} \mathrm{C}$, the residual is $0 \%$. Maximum decomposition rate temperature is $490^{\circ} \mathrm{C}$. These showed the better plasticizing of film, and the lower initial temperature of dissociation. Reduction in molecular weight leads to lower initial temperature of dissociation; Minimum decomposition temperature is $360^{\circ} \mathrm{C}$ which shows pyrolysis temperature of film is relatively high. This temperature has great effect on the resistance to thermal degradation caused by overheating because of instantaneous friction heat production.

\subsection{Surface Resistance}

As we known, polymer materials, of course, UHMW-PE film have good insulation properties. In the usage of acid condition, the antistatic property of UHMW-PE film surface maybe modified by dip-molding method after raising surface groups of UHMW-PE film. The change of surface resistance of the UHMW-PE film modifica-

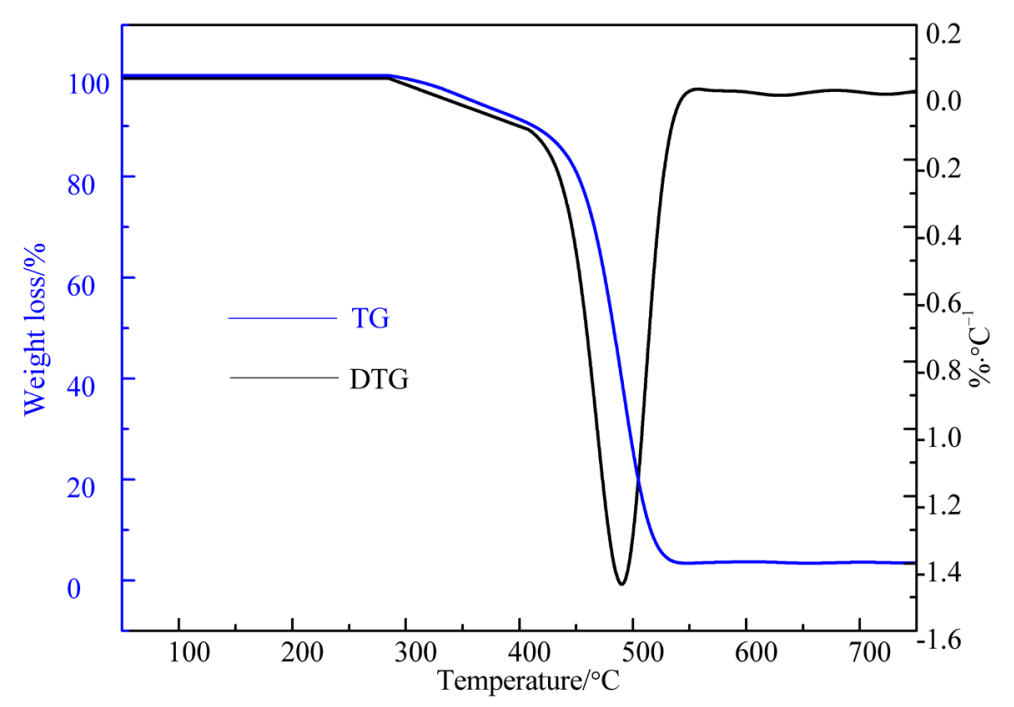

Figure 1. TG and DTG curves of UHMW-PE film.

Table 1. Some physico-chemical properties of UHMW-PE film.

\begin{tabular}{cccc}
\hline $\begin{array}{c}\text { Thickness } \\
(\mu \mathrm{m})\end{array}$ & $\begin{array}{c}\text { Density } \\
\left(\mathrm{kg} \cdot \mathrm{m}^{-3}\right)\end{array}$ & $\begin{array}{c}\text { Gas permeability } \\
\left(\mathrm{cm} 3 \cdot \mathrm{m}^{-2} 24 \mathrm{~h} \cdot 0.1 \mathrm{MPa}\right)\end{array}$ & $\begin{array}{c}\text { Tensile strength } \\
(\mathrm{MPa})\end{array}$ \\
\hline $190.00 \pm 10.00$ & 0.94 & 546.57 & 37.22 \\
\hline
\end{tabular}


tion with different immersion time (12 h, 9 h, 6 h, 3 h, 0 h), various concentrations (85 wt\%, $30 \mathrm{wt} \%$, $20 \mathrm{wt} \%$, $10 \mathrm{wt} \%, 0 \mathrm{wt} \%$ ) is in Table 2, Table 3, respectively.

According to Table 2, surface resistance of UHMW-PE films have increased while raised the immersion time especially from $3 \mathrm{~h}$ to $6 \mathrm{~h}$. The surface resistance of film up to $1.0 \times 10^{14} \Omega$ is modified by $85 \mathrm{wt} \% \mathrm{H}_{3} \mathrm{PO}_{4}$. As the immersion time increasing, the conductivity of the films decreased. Interestingly, surface resistance of UHMW-PE films soaking in $38 \% \mathrm{HCl}, 85 \% \mathrm{H}_{3} \mathrm{PO}_{4}$ for $3 \mathrm{~h}$ is significantly lower by 3,6 orders of magnitude, respectively than that without soaking. But, surface resistance of UHMW-PE films is more than that untreated UHMW-PE film while immersion time is more than $6 \mathrm{~h}$. For this phenomenon, in the case of the insufficient immersion time, UHMW-PE film appears some surface corrosion and carbon deposition. While immersion time is long enough, the UHMW-PE film's surface achieves a balance.

Table 3 shows the surface resistance of UHMW-PE films has a little increased while gradually diluted $\mathrm{HCl}$ and $\mathrm{H}_{3} \mathrm{PO}_{4}$ for $6 \mathrm{~h}$. Changing $\mathrm{H}_{3} \mathrm{PO}_{4}$ concentration from $85 \mathrm{wt} \%$ to10 wt $\%$, the surface resistance is from $1.0 \times$ $10^{13} \Omega$ to $4.0 \times 10^{13} \Omega$. Changing $\mathrm{HCl}$ concentration from $38 \mathrm{wt} \%$ to $10 \mathrm{wt} \%$, the surface resistance is from $1.5 \times$ $10^{13} \Omega$ to $5.0 \times 10^{14} \Omega$. In this sense, changing the concentration of immersion solution has little influence on the surface resistance of the UHMW-PE film. Whether the solution is superacid or weakacid, with enough immersed time, surface resistance changes a little, the carbon deposition amount on UHMW-PE film surface reaches equilibrium. Therefore, UHMW-PE film can be used in above acid.

\subsection{Contact Angle}

Contact angle obtain the material is hydrophilic or hydrophobic. The volume of liquid droplet is always $4 \times 10^{-6}$ L. Each sample was measured 5 times at $25^{\circ} \mathrm{C}$. Then discarded the highest and lowest contact angle, and took the approximate average contact angle. In this part, the deviation of contact angle measurement is $\pm 2^{\circ}$. The contact angle of the UHMW-PE films modification with various concentrations ( $0 \mathrm{wt} \%, 10 \mathrm{wt} \%, 20 \mathrm{wt} \%$, $30 \mathrm{wt} \%$, $85 \mathrm{wt} \%$ ) for 3 h, different immersion time ( 0 h, 3 h, 6 h, 9 h, 12 h) in 20 wt $\% \mathrm{CH}_{3} \mathrm{COOH}$ is in Figure 2(a), Figure 2(b), respectively.

Figure 2(a) shows the change of $\mathrm{H}_{3} \mathrm{PO}_{4}$ concentration has an influence on the UHMW-PE films contact angle with same immersion time. The UHMW-PE films contact angle has decreased while added solution concentration from $10 \mathrm{wt} \%$ to $85 \mathrm{wt} \%$. We also obtain the untreated UHMW-PE film contact angle is higher than that modified by $\mathrm{H}_{3} \mathrm{PO}_{4}$. The data imply that the films are hydrophobic materials. Figure 2(b) shows changing immersion time of $\mathrm{CH}_{3} \mathrm{COOHhas}$ an influence on the UHMW-PE films contact angle with same concentration. The contact angle of UHMW-PE films has increased while added the immersion time from $3 \mathrm{~h}$ to12 h. Especially, the contact angle of film is $115.0^{\circ}$ when immersion time is $12 \mathrm{~h}$. Notably, the contact angles are both less than $90^{\circ}$ while immersion time is $3 \mathrm{~h}, 6 \mathrm{~h}$, respectively; this point illustrates they have being hydrophilic. The result is owing to insufficient immersion time.

Associating Figure 2(a) with Table 3, the higher solution concentration UHMW-PE films immersed, the contact angle and surface resistance become lower. Associating Figure 2(b) with Table 2, the longer immersion

Table 2. Rs immersed in solutions with different immersion time.

\begin{tabular}{ccccc}
\hline Immersion time & Before modified & $3 \mathrm{~h}$ & $6 \mathrm{~h}$ & $9 \mathrm{~h}$ \\
Items & $4.3 \times 10^{12}$ & $7.0 \times 10^{9}$ & $1.5 \times 10^{13}$ & $6.0 \times 10^{13}$ \\
$38 \mathrm{wt} \% \mathrm{HCl}$-Rs $(\Omega)$ & $2.8 \times 10^{13}$ & $1.0 \times 10^{7}$ & $1.0 \times 10^{13}$ & $8.0 \times 10^{13}$
\end{tabular}

Note: Rs: Surface resistance; 38 wt\% $\mathrm{HCl}-\mathrm{Rs}(\Omega)$, 85 wt $\% \mathrm{H}_{3} \mathrm{PO}_{4}$-Rs $(\Omega)$ means surface resistance of UHMW-PE films immersed in 38 wt $\%$ HCl, 85 wt $\% \mathrm{H}_{3} \mathrm{PO}_{4}$, respectively. The unit of surface resistance is " $\Omega$ ". $38 \mathrm{wt} \%$, $85 \mathrm{wt} \%$ is maximum concentration of $\mathrm{HCl}_{3} \mathrm{H}_{3} \mathrm{PO}$, respectively to buy.

Table 3. Rs immersed in solutions with various concentrations.

\begin{tabular}{|c|c|c|c|c|c|}
\hline $\begin{array}{l}\text { wt } \%(6 \mathrm{~h}) \\
\text { Items }\end{array}$ & 85 & 38 & 30 & 20 & 10 \\
\hline $\mathrm{H}_{3} \mathrm{PO}_{4}$-Rs $(\Omega)$ & $1.0 \times 10^{13}$ & -- & $1.5 \times 10^{13}$ & $3.0 \times 10^{13}$ & $4.0 \times 10^{13}$ \\
\hline $\mathrm{HCl}-\mathrm{Rs}(\Omega)$ & -- & $1.5 \times 10^{13}$ & $2.5 \times 10^{13}$ & $3.0 \times 10^{13}$ & $5.0 \times 10^{14}$ \\
\hline
\end{tabular}

Note: $30 \mathrm{wt} \%, 20 \mathrm{wt} \%, 10 \mathrm{wt} \%$ were diluted from maximum concentration solutions. 
time UHMW-PE films immersed, the contact angle and surface resistance become higher.

\subsection{Wear Testing of UHMW-PE film}

With the increasing of number of turning, how the wear resistance of UHMW-PE film changes. The data of UHMW-PE film's mass and contact angle after rubbed 1000r, 1500r, 2000r, 2500r, 3000r show in Figure 3.

According to Figure 3, UHMW-PE film has a high wear resistance. The change of mass is $0.0020 \mathrm{~g}, 0.0028 \mathrm{~g}$, $0.0037 \mathrm{~g}, 0.0045 \mathrm{~g}$, and $0.0061 \mathrm{~g}$ after rubbed at 1000r, 1500r, 2000r, 2500r, 3000r, respectively. As the number of turning increased, the contact angle becomes increase and more than $90^{\circ}$. Especially, the contact angle is $111.5^{\circ}$ when the UHMW-PE film is rubbed at 3000r. It has a good hydrophobic property.

\subsection{SEM of UHMW-PE Film}

After modification by acidation impregnation and rattler testing of UHMW-PE, the surface resistance and contact angle have changed. The surface morphology of untreated UHMW-PE film, the film modified by $85 \mathrm{wt} \%$ $\mathrm{H}_{3} \mathrm{PO}_{4}$ for $12 \mathrm{~h}$, and the film rubbed at 3000r was observed by SEM micrographs amplify 2000 in Figure 4(a)-(c), respectively.

Figure 4(a) shows surface morphology of untreated UHMW-PE film, there is some folded. The surface is crude and unsmooth. This is owing to an uncertain and undetermined thickness. Figure 4(b) is UHMW-PE film

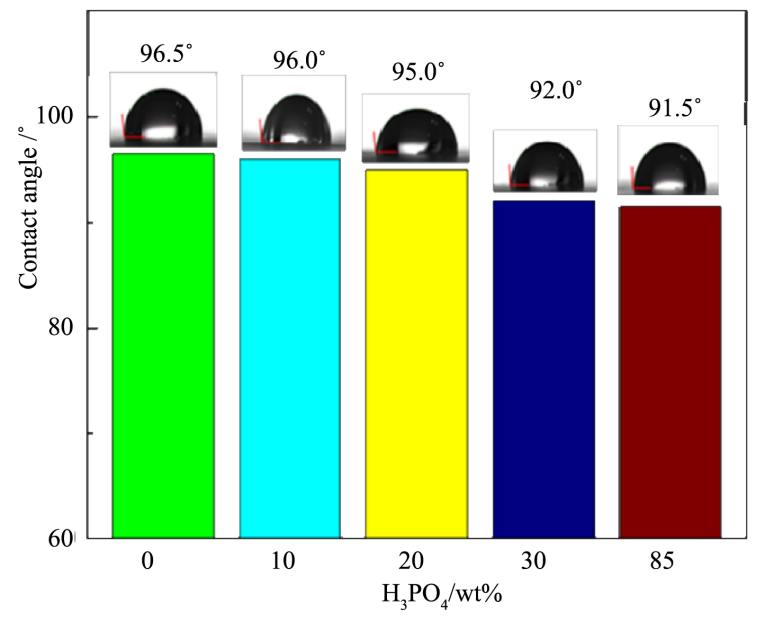

(a)

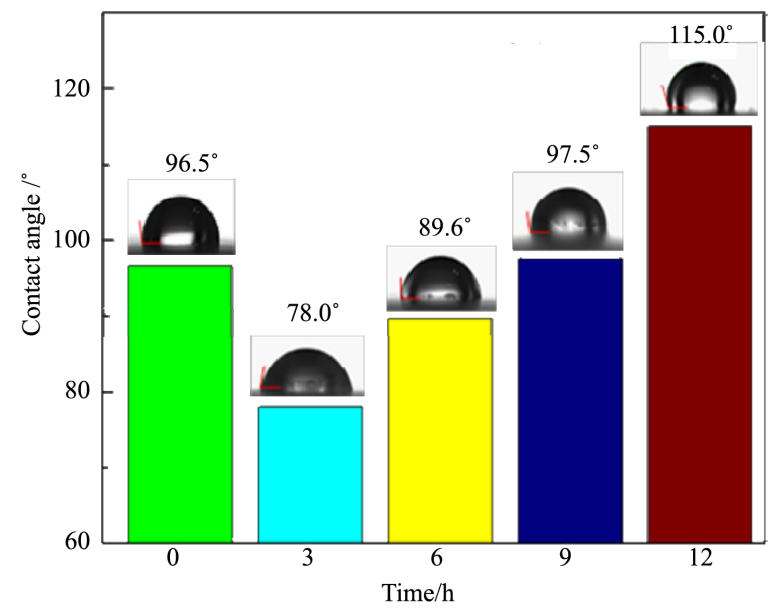

(b)

Figure 2. Contact angle of films by acidation modification.

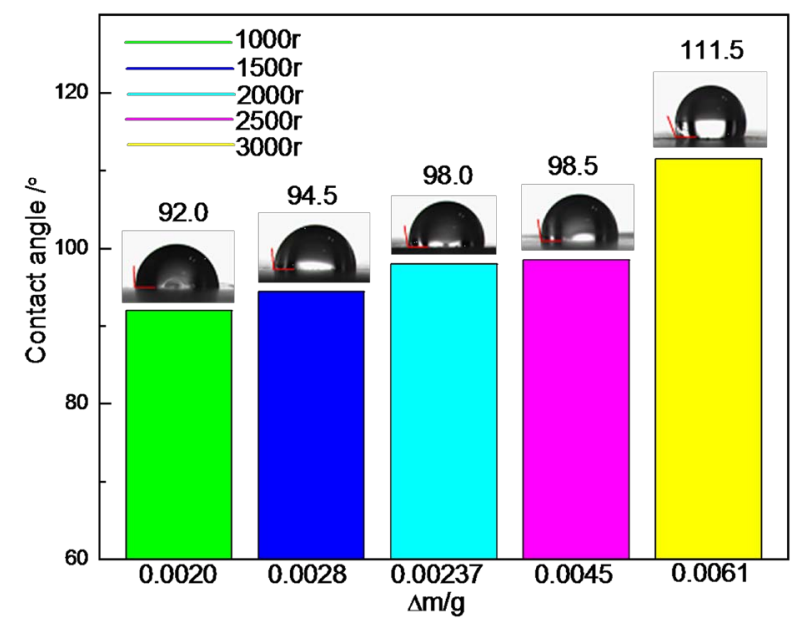

Figure 3. Contact angle of film by rattler testing. 

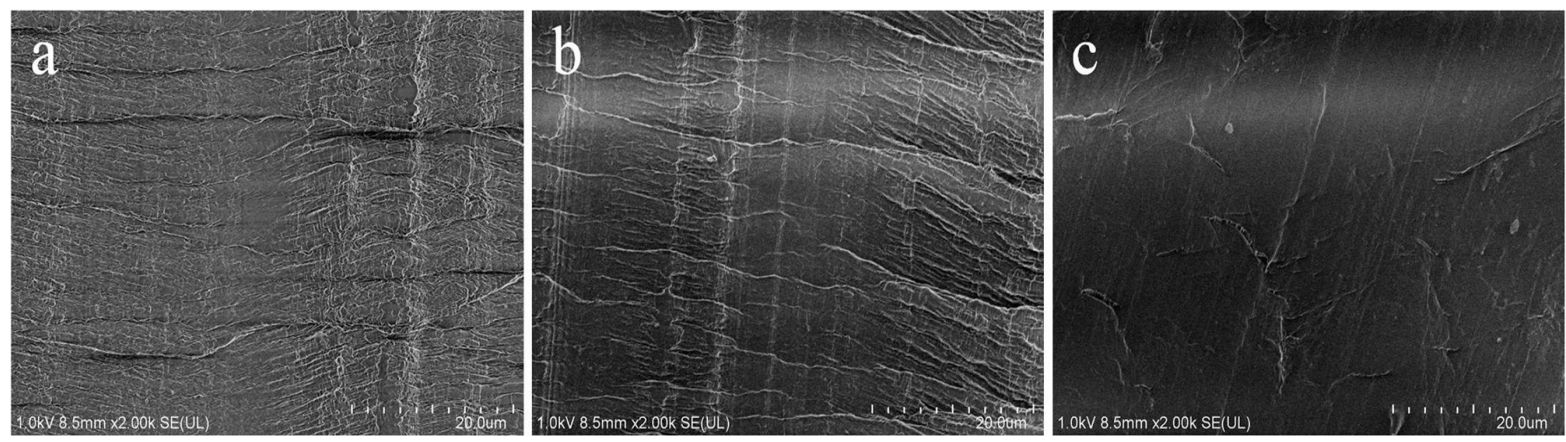

Figure 4. SEM micrographs of surface of UHMW-PE.

immersed in $85 \mathrm{wt} \% \mathrm{H}_{3} \mathrm{PO}_{4}$ for $12 \mathrm{~h}$. It has just a little more folded and rough than that untreated UHMW-PE film. The result is due to the surface corrosion and carbon deposition amount of UHMW-PE film after immersed in solutions. But this will not affect the mechanical properties of the UHMW-PE film. Figure 4(c) shows surface morphology of UHMW-PE film rubbed 3000r. Figure 4(c) appears a smooth, and no wrinkles surface. This is because of mill wheel rubs the UHMW-PE film following the clockwise direction. After wear testing, the uneven thickness surface of UHMW-PE film was rubbed to be flat. And this is in perfect with film rubbed 3000r has higher contact angle $\left(111.5^{\circ}\right)$.

\section{Conclusions}

Through the results and discussion about the UHMW-PE film, we can get:

- UHMW-PE film has good mechanical properties. The values of gas permeability, tensile strength, elongation at break, and the temperature of dissociation at weight loss $5 \%$ was $546.57 \mathrm{~cm}^{3} \cdot \mathrm{m}^{-2} 24 \mathrm{~h} \cdot 0.1 \mathrm{MPa}, 37.22$ $\mathrm{MPa}, 368.00 \%, 360^{\circ} \mathrm{C}$, respectively.

- After modified by acid with different immersion time, various concentrations and various solutions and rattler testing, the surface resistance has little change. This means UHMW-PE film can be used in acid that we have investigated.

UHMW-PE film has excellent wearing resistance and good hydrophobic that apply in biomedical, chemical engineering, electronics, mining industry and transportation.

\section{References}

[1] Kozakiewicz, M., Elgalal, M., Walkowiak, B. and Stefanczyk, L. (2013) Technical Concept of Patient-Specific, Ultrahigh Molecular Weight Polyethylene Orbital Wall Implant. Journal of Cranio-Maxillofacial Surgery, 41, 282-290. http://dx.doi.org/10.1016/j.jcms.2012.10.007

[2] Chen, Y.F., Qi, Y.Y., Tai, Z.X., Yan, X.B., Zhu, F.L. and Xue, Q.J. (2012) Preparation, Mechanical Properties and Biocompatibility of Graphene Oxide/Ultrahigh Molecular Weight Polyethylene Composites. European Polymer Journal, 48, 1026-1033. http://dx.doi.org/10.1016/j.eurpolymj.2012.03.011

[3] Petrican, M., Duscher, B., Koch, T. and Archodoulaki, V.M. (2015) Tribological Investigations on Virgin and Accelerated Aged PE-UHMW. Tribology International, 87, 151-159. http://dx.doi.org/10.1016/j.triboint.2015.02.024

[4] Nguyen, L.H., Ryan, S., Cimpoeru, S.J., Mouritz, A.P. and Orifici, A.C. (2015) The Effect of Target Thickness on the Ballistic Performance of Ultra High Molecular Weight Polyethylene Composite. International Journal of Impact Engineering, 75, 174-183. http://dx.doi.org/10.1016/j.ijimpeng.2014.07.008

[5] Guedes, R.M., Pereira, C.M., Fonseca, C.A. and Oliveira, M.S.A. (2013) The Effect of Carbon Nanotubes on Viscoelastic Behaviour of Biomedical Grade Ultra-High Molecular Weight Polyethylene. Composite Structures, 105, $263-268$. http://dx.doi.org/10.1016/j.compstruct.2013.05.027

[6] Huang, Y.F., Xu, J.Z., Li, J.S., He, B.X., Xu, L. and Li, M.Z. (2014) Mechanical Properties and Biocompatibility of Melt Processed, Self-Reinforced Ultrahigh Molecular Weight Polyethylene. Biomaterials, 35, 6687-6697. http://dx.doi.org/10.1016/j.biomaterials.2014.04.077

[7] Zheng, Z., Huang, X.C., Li, Y., Yang, N.C, Wang, X.L. and Shi, M.W. (2012) Influence Factors of Internal Structure and Interfacial Compatibility of UHMWPE Fiber/SEBS Resin Composites: Processing Parameters, Structure of Fiber and Nature of Resin. Composites Part B, 43, 1538-1544. http://dx.doi.org/10.1016/j.compositesb.2011.11.011 
[8] Zhang, W., Hu, Z.S., Zhang, Y.A., Lu, C.H. and Deng, Y.L. (2013) Gel-Spun Fibers from Magnesium Hydroxide Nanoparticles and UHMWPE Nanocomposite: The Physical and Flammability Properties. Composites Part B, 51, 276281. http://dx.doi.org/10.1016/j.compositesb.2013.03.014

[9] Collins, M.N., Dalton, E., Schaller, B., Leahy, J.J. and Colin, B. (2012) Crystal Morphology of Strained Ultra High Molecular Weight Polyethylenes. Polymer Testing, 31, 629-637. http://dx.doi.org/10.1016/j.polymertesting.2012.03.009

[10] Senatov, F.S., Gorshenkov, M.V., Tcherdyntsev, V.V., Kaloshkin, S.D. and Sudarchikov, V.A. (2015) Fractographic Analysis of Composites Based on Ultra High Molecular Weight Polyethylene. Tribology International, 87, 151-159. http://dx.doi.org/10.1016/j.compositesb.2013.08.083

[11] Wen, S.G., Shen, Y., Wang, J.H., Liu, H.B., Xu, Q. and Song, S.G. (2011) Surface Modification of the UHMW-PE Film Processing by Hot Compression Molding. Advanced Materials Research, 239, 703-706. http://dx.doi.org/10.4028/www.scientific.net/AMR.239-242.703 